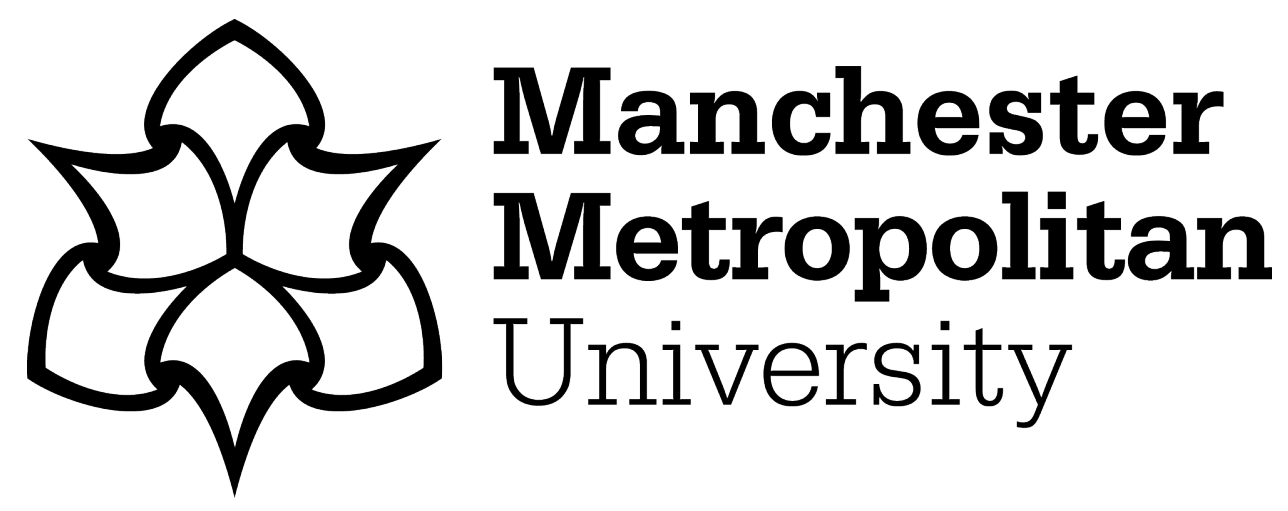

Veer Ramjeawon, $P$ and Rowley, J ORCID logoORCID: https://orcid.org/0000-0003-3437-6914 (2018) Knowledge management in higher education institutions in Mauritius. International Journal of Educational Management, 32 (7). pp. 1319-1332. ISSN 0951-354X

Downloaded from: https://e-space.mmu.ac.uk/623231/

Version: Accepted Version

Publisher: Emerald

DOI: https://doi.org/10.1108/lJEM-05-2017-0129

Please cite the published version 


\title{
Knowledge Management in Higher Education Institutions in Mauritius
}

\begin{abstract}
Purpose: This study contributes to research on knowledge management (KM) in higher education institutions (HEIs) by studying its processes, knowledge creation, knowledge sharing and knowledge transfer, in Mauritius.

Design/methodology/approach: Semi-structured interviews were conducted with senior staff in the main public and private HEIs in Mauritius. Questions focused on KM strategy and processes. Interviews were recorded and transcribed prior to thematic analysis.

Findings: Although participants could discuss KM processes, none of the participating institutions had a KM strategy. All institutions are involved in knowledge creation and acquisition, knowledge sharing, and knowledge transfer. In addition to research, knowledge was regarded as being created through teaching and learning activities, consultancies, organisational documentation and acquisition from external sources. Knowledge is shared among peers during departmental and curriculum meetings, through annual research seminars and during conferences and publications in journals. Knowledge transfer with industry through consultancies is restricted to a few public HEIs. In the remaining HEIs, knowledge transfer is limited to their students joining the workforce and to organising tailor-made courses and training programmes for public and private institutions. The study also provides evidence that some processes and activities contribute to more than one of knowledge creation, sharing and transfer.

Originality/value - This study contributes to the very limited body of research into KM processes in countries with developing higher education sectors. In addition, this research disaggregates the processes associated with knowledge creation, sharing and transfer, whilst also examining the relationship between them.
\end{abstract}

Keywords: Knowledge Management; Knowledge management processes; Knowledge creation; Knowledge sharing; Knowledge transfer; Higher Education; Universities

Paper type: Research Paper 


\section{Introduction}

It is widely accepted that the main role of Higher Education Institutions (HEIs) is to create and share knowledge. However, these roles of universities have significantly changed over time due to two main revolutions. Universities, which were originally created with the purpose of teaching, added research to their role in the first academic revolution in the late $19^{\text {th }}$ century. Later, a second revolution added economic development, and enterprise to their missions (Schmitz et al., 2014). In knowledge-based societies, universities are being called upon to play a vital role in the innovation system of a country as one of the partners in the "Triple Helix", alongside government and industry (Etzkowitz and Leydesdorff, 2000). This new dynamic academic environment requires successful higher education institutions to constantly create new knowledge and disseminate it widely (Adhikari, 2010). Bano and Taylor (2014) argue that this change in role for HEIs, from knowledge creation to application of knowledge and collaboration with other sectors of the economy, could have both positive and negative effects. On one hand, it can make the universities more entrepreneurial and innovative (Schmitz et al., 2014), whilst, on the other hand, it could erode their academic freedom and independence (Bano and Taylor, 2014).

Despite the centrality of knowledge and its management to the contribution of universities, there has been very little acknowledgement that they are knowledge intensive organisations (Schmitz et al., 2014), and limited research into knowledge processes and their management in universities. Previous studies in developed higher education sectors, in Japan, Iran, Malaysia, UK and India, confirm that universities are involved in knowledge creation (Tian et al., 2009; Siadat et al., 2012), knowledge sharing (Cheng et al., 2009; Fullwood et al., 2013), and knowledge transfer (Gertner et al., 2011; Gera, 2012). Furthermore, studies in developing economies and on the relationships between KM processes in HEIs, as have been carried out in private sector (Andreeva and Kianto, 2011; Lee et al., 2013), are very few. Mauritius is a country

with a developing higher education sector that includes both public and private institutions. The Government of the Republic of Mauritius has a vision for transforming Mauritius into a knowledge hub and a regional centre of excellence for higher education, such that the sector makes a significant contribution to Mauritius' economic competitiveness. As such, it provides an interesting context for this research.

The purpose of the research reported in this paper is to contribute to the very limited body of research into KM processes in countries with developing higher education sectors. In addition, this research disaggregates the processes associated with knowledge creation, sharing and transfer, whilst also examining the relationship between them.

The next section of this article summarizes previous research on knowledge management and its processes, with specific reference to research in higher education institutions. The following section explains the methodology, including the approach to data collection and analysis. Next, findings are reported and discussed. Finally, conclusions and recommendations for practice and further research are outlined. 


\section{Literature review}

\subsection{Knowledge management strategy in higher education institutions}

Higher Education Institutions (HEIs) have been involved in knowledge management since they were established centuries ago, and the three missions of modern universities globally, research, education, and service to society, are closely linked with knowledge creation, knowledge dissemination and knowledge transfer, respectively (Rowley, 2000; Alexandropoulou et al., 2009; Ramachandran et al., 2009; Fullwood et al., 2013). The arrival of the knowledge economy has brought HEIs centre stage and in a global competitive environment, it is becoming very important for them to manage their knowledge processes within the context of a deliberate knowledge management strategy. However, past studies identify a lack of an explicit knowledge management strategy in universities (Cranfield and Taylor, 2008), even though, having a KM strategy could enable universities to function more effectively and efficiently, and enable them to improve their quality and enhance their competitiveness (Trivella and Dimitrios, 2015). As a prerequisite, it is important to understand the extent of engagement with KM processes, viz, knowledge creation, sharing and transfer, and their relationship in HEIs.

\subsection{Knowledge management processes in higher education institutions}

Knowledge management processes govern the creation, dissemination and utilization of knowledge to fulfil organisational objectives (Adhikari, 2010). Dalkir (2011) has proposed an integrated knowledge management cycle, where the knowledge created/captured is assessed before sharing and dissemination, and then it is contextualized before use and application. The experience gained in using knowledge provides inputs that update the knowledge, thereby creating new knowledge.

This paper mainly focuses on three KM processes: k-creation, k-sharing and k-transfer, which are closely linked to the three main roles of universities: research, teaching and service to society, respectively. These are further elaborated below:

Knowledge Creation (KC) is the development of new knowledge and know-how and the formation of new ideas through interactions between explicit and tacit knowledge in individual human minds (Nonaka, 1994). According to Alexandropoulou et al. (2009) knowledge creation corresponds with the research mission of the universities with its aim of expanding the boundaries of human knowledge and promoting creativity through the production of doctoral researchers and codified knowledge. Similarly, Dorri and Talebnejod (2008), as cited in Siadat et al. (2012), consider knowledge creation as one of the most important missions of universities today, the need for which can be assessed from the external dimension (response to the needs of society) and internal dimension (improvement in the quality of education, promotion of the place of university, and increase in income). Rowley (2000) and Serban and Luan (2002) are also of the view that knowledge creation is the core process of knowledge management and all organisations, especially higher education institutions, create knowledge through a variety of means, such as, scientific discovery or discussion. This is supported by Siadat et al. (2012) who regard professors' scientific socialization, the combination of scientific findings, and publishing findings of research, as knowledge creation. Knowledge 
acquisition is also reported in the literature as a process of development and creation of insights, skills, and new knowledge from outside by either purchasing it, or hiring experts, or licensing patents, and by creating it inside the organization through formal research activities and by acquiring experienced experts (Sohail and Daud, 2009 and Adhikari, 2010). In addition, it is essential for HEIs to capture this knowledge through digitization, documentation and storage in knowledge repositories for future generations of scholars and researchers (Rowley, 2000). Enhancing knowledge creation in academia also requires improving the creative environment, including both "soft" and "hard" aspects, by using personalization and technology strategies (Tian et al., 2009).

Based on past literature, for this article 'knowledge creation' refers to 'the search for and generation of new knowledge by academics for their personal advancement and to enhance the organizational knowledge base for service to society'.

Knowledge Sharing (KS) is considered as the most important and challenging process of knowledge management (Serban and Luan, 2002; Arntzen et al., 2009; Sohail and Daud, 2009). It is a natural activity of academic institutions, in the form of seminars, conferences and publications, suggesting that there is a willingness to share knowledge (Cheng et al., 2009). Fullwood et al. (2013) are also of the view that there is an implicit knowledge sharing culture in universities and academics are engaged in knowledge sharing related to research, and teaching and learning activities. Contrary to this view, and despite the importance of knowledge sharing in universities in strengthening research and teaching activities, "knowledge hoarding" is also prevalent amongst many academics (Cheng et al., 2009; Goh and Sandhu, 2013). A culture and an environment must be present to facilitate knowledge sharing through nurturing teamwork, networking and collaboration (Arntzen et al., 2009; Tian et al., 2009; Fullwood et al., 2013; Howell and Annansingh, 2013).

Knowledge sharing, in this study, refers to 'the exchange of knowledge between academics and researchers among peers within a university, in order to enhance their knowledge base and that of their universities'.

Knowledge Transfer (KT), which is considered as the 'third mission' of higher education activity, along with research and teaching, involves the transfer of knowledge to non-academic partners, such as, industry, public sector and the general public, and service to society by job creation through spin-off companies (Alexandropoulou et al., 2009). Universities, worldwide are responding to this new and emerging needs of society and of the economy, by focusing on knowledge transfer and skills development (Bano and Taylor, 2014). However, according to Gertner et al. (2011), knowledge transfer from academia to industry requires time and space in which to develop a shared understanding, nurture relationships and identify mutual interests among the partners. Universities in developing countries generally face greater challenges in such alliances, because they look to the Government to provide the overall framework for developing these linkages, which requires the formulation of policy directions and reward systems. In addition whilst some academics in developing countries do make links with industry, business and non-governmental organisations, these links are few and mostly informal (Bano and Taylor, 2014). In practice, the universities in developing countries consider publications, presentations, web sites, white papers, teaching and learning activities, policies, and reports as 
mechanisms to disseminate/transfer knowledge (Ramachandran et al., 2009). Gera (2012) suggests that there has been very little transfer of research knowledge due to the inherent barriers, at an individual and organizational level, in its creation, diffusion, adoption and utilization by practitioners, and a lack of industry orientation of academics. He is also of the view that the knowledge created in HEIs through research is perceived as ambiguous, cognitive, abstract and intangible and requires significant transformation before it is adopted effectively by industry.

Knowledge transfer, in this study, refers to 'the dissemination of knowledge created by the academics and researchers within a university to external stakeholders or partners for its application and use and for service to society'.

\subsection{Relationships between knowledge management processes}

Most previous studies on KM processes in HE focus on one or two KM processes (Arntzen et al., 2009; Cheng et al., 2009; Sohail and Daud, 2009; Tian et al., 2009; Siadat et al., 2012; Fullwood et al., 2013; Goh and Sandhu, 2013; Howell and Annansing, 2013) and very few studies consider relationships between two or more KM processes (Tian et al., 2009; Gertner et al., 2011; Gera, 2012). In an empirical study in Japan, Tian et al. (2009) reported that the creative environment for knowledge creation requires a knowledge sharing culture, and Gera (2012) argued that knowledge transfer is restricted due to barriers in knowledge creation which can be improved through internal learning, that is, knowledge sharing. In another study in the UK, Gertner et al. (2011) discuss university-industry collaboration (KT) through the development of communities of practice (CoPs), an approach to knowledge sharing that offers opportunities not only to transfer knowledge but also for the creation of new knowledge. In another study, Ramachandran et al. (2009) investigated the practice of six KM processes (knowledge creation, capture, organisation, storage, dissemination, and application) in public and private HEIs of Malaysia, however, the relationships between the processes were not examined.

There is sufficient evidence that knowledge processes are closely interrelated with each other and have an impact on firms' innovation (Andreeva and Kianto, 2011; Lee et al., 2013). In an empirical study carried out in private companies in Finland, Russia and China, Andreeva and Kianto (2011) demonstrate that even though all knowledge processes (knowledge creation, documentation and storage, knowledge sharing and knowledge acquisition) have a beneficial impact on innovation, knowledge creation impacts innovation the most, and is facilitated by documentation and knowledge sharing. Furthermore, knowledge intensity moderates the relationship of documentation and knowledge sharing with knowledge creation. The study by Lee et al. (2013), which investigated the interrelationship between the different KM dimensions in Malaysian firms, found positive and significant relationships among the three dimensions of KM, knowledge acquisition, knowledge sharing and knowledge application. Finally, Paulin and Suneson (2012: 81) suggest that 'the terms knowledge transfer and knowledge sharing are blurry and sometimes used synonymously or considered to have overlapping content' and 'have different meanings depending on the authors' views'.

Despite the significant research interest in the KM processes in universities, very few previous studies on knowledge management in universities have covered the three major KM processes: 
knowledge creation, knowledge sharing and knowledge transfer, which are closely linked to the three missions of universities. Furthermore, there has been very limited research on the interrelationship between KM processes in HE or in private firms. Hence, the purpose of this study is to contribute to knowledge on knowledge management in universities, through a study based on Mauritius, a country with a developing higher education sector. Specifically, this study will examine the three knowledge management processes and their interrelationships.

\section{Methodology}

The higher education sector in Mauritius, according to the Tertiary Education Commission (TEC) website (http://tec.intnet.mu/overview), extends to 65 institutions, including ten public HEI's and some 55 private HEI's. The ten public HEIs include four universities. The private HEI's are mostly local branches of overseas institutions and/or affiliated with overseas institutions from, for example, Australia, India, South Africa, and UK. This study used interviews with key informants in seven of these HEI's to gather insights into the knowledge management strategies and processes associated with knowledge creation, sharing and transfer. Since knowledge management is a relatively new concept for HEIs in developing countries, including Mauritius, qualitative research using semi-structured interviews that seeks to generate in-depth insights was deemed to be appropriate (Saunders et al., 2016). Furthermore, an interpretivist stance that is inductive in nature was adopted in this study.

An interview schedule was designed and piloted through meetings with three senior academics with vast experience in research and research management, including two Professors (former deans) and one head of institution. The questions in the interview schedule aimed to:

- inquire into the KM strategies of public and private HEIs of Mauritius, and

- explore the understanding of senior academics and researchers/ research managers on KM processes: knowledge creation, knowledge sharing and knowledge transfer, in HEIs

More specifically, the questions raised during the semi-structured interviews were:

1. Whether the participants were familiar with the term 'Knowledge Management'?

2. Whether their institutions had a written KM strategy?

3. How was knowledge created and/or acquired in their institution?

4. How was the knowledge created through research stored and made available to others?

5. How was knowledge shared among academics and researchers within their institution?

6. How was knowledge transferred from their institution to outside partners?

Face-to-face interviews were conducted with eleven senior academics involved in research and/or research management, including heads of institution, heads of faculty, heads of academics, senior academics and researchers (Table 1). Heads of institutions were contacted formally in order to obtain approval to interview them or their senior colleague(s). Prior to each interview, the researcher provided each interviewee with information on the study, the interview guide and knowledge management terminology and definitions to facilitate discussion during the interview. Permission to record each interview was obtained through a consent form. Participation in the study was voluntary and interviewees were informed that interviews and any 
documents provided during and after the interview were confidential; interviewees were free to decline to answer any questions or to withdraw from the interview at any time.

Table 1: Participants

\begin{tabular}{|l|l|}
\hline Institution & Brief description of participants \\
\hline Public Universities \\
\hline A1 & $\begin{array}{l}\text { Senior academics and researchers at Associate Professor and } \\
\text { Professor level, former Heads of Departments and Heads of } \\
\text { Faculties }\end{array}$ \\
\hline A3 & Head of Institution \\
\hline B1 & Head of Faculty \\
\hline B2 & Academic researching in KM \\
\hline B3 & Head of Faculty \\
\hline C & Head of Institution \\
\hline D & Head of Academics \\
\hline Private Universities \\
\hline E & Head of Institution \\
\hline F & Head of Academics \\
\hline G &
\end{tabular}

The interviews lasted between 45 minutes to an hour. Each interview was transcribed using Microsoft Word. Interview transcripts were reviewed leading to data reduction, summary notes made, and thematic analysis was undertaken by identifying patterns and themes in the collected study data. (Miles and Huberman, 1994). Although, the analysis was guided by the themes in the interview schedule, such as KM strategy, knowledge creation, knowledge sharing and knowledge transfer, it was not restricted to them, and an inductive approach was used for identification of sub-themes. This was supported by concept maps, a visualization technique, to create models and analyse themes and sub themes (Kinchin and Streatfield, 2010).

\section{Findings}

\subsection{Knowledge Management Strategy}

Almost all participants, except one, were familiar with the term Knowledge Management, however, they were of the view that their institutions do not have a written KM strategy, under the title "knowledge management strategy" in their institutional strategic plans.

The following quotes reflect the KM familiarity and status on KM strategy at public and private HEIs in Mauritius.

"There is no explicit KM strategy" (A3).

"No, we don't have KM strategy as such on paper, but we practice it" (E). 


\subsection{Knowledge Management Processes}

\subsubsection{Knowledge Creation}

Participants agreed that one of the main aims of higher education institutions is knowledge creation. The following quotes from participants support the knowledge creation function of HEIs.

"The role of the university is basically to create and disseminate knowledge" (A1).

"Creation of knowledge is the core business of universities. Universities must contribute to the economic development of the country and it can be done through the creation of knowledge which is relevant to the country" (A2).

"Knowledge is created through all stakeholders in an institution, when the knowledge of all key actors (academics, researchers and students) comes together it becomes a rich source for the institution" $(C)$.

In addition to research, participants reported that knowledge was also created through teaching and learning activities, consultancies, organisational documentation and acquisition from external sources.

Figure 1a and the following quotes summarize the knowledge creation scenario in public and private HEIs of Mauritius:

[Insert Figure 1a near here]

"Knowledge is created from the knowledge of lecturers which they acquire from text books and journals and from their experience of life and their teaching experiences and from all other sources to which they have recourse to. [And,] through research that they do, or if they supervise students, or through consultancies. They also attend meetings in and out of the university; they also get knowledge from there, [and from] international conferences, workshops and committees. All these are the sources of knowledge creation" (B1).

"When people talk about creation of knowledge [they] tend to restrict [it] to research. But to my mind you also create lots of knowledge during your teaching and learning activities." (A2).

"We create knowledge through our consultancies, when we interact with other people, interaction with our stakeholders" (A1).

"The other knowledge in [the] university would be ... a range of rules and regulations within the university, academic policies and procedures, hand books and staff guide, telling new staff what they have to do and what we expect of them" $(F)$. 
During the interviews, the participants were using the terms 'knowledge creation' and 'knowledge acquisition' interchangeably. They were also of the view that knowledge acquisition from external sources ultimately led to knowledge creation for their institution.

Being a developing economy with an emerging higher education sector, the HEIs in Mauritius are primarily teaching and learning institutions. A few are now aiming to become 'research-led' institutions and are involved in knowledge creation. Most of the HEIs 'acquire' knowledge from various external sources as indicated in Figure $1 \mathrm{~b}$ and summarized in the following quotes:

[Insert Figure 1b near here]

"We join the university as academics with acquired knowledge from our university where we studied" $(C)$.

"Our staff they acquire knowledge through books through internet sites or through their own experience" (A1).

"Knowledge is also acquired through our internal and external committees, where our staff go ... and bring back to the organisation. Because when people come together in the committee at the senate level, at the council level and external committees, knowledge is created" (A1).

"The staff also get knowledge from international conferences, workshops and committees" (B1).

"We are learning from external examiners and visiting experts" (A3).

"We also acquire knowledge from our international academic partners, where we take their materials and impart to Mauritian students" (E).

\subsubsection{Knowledge Sharing}

Participants from both public and private institutions reported on knowledge sharing mechanisms as summarized in Figure 2.

[Insert Figure 2 near here]

A number of knowledge sharing mechanisms were identified, as elaborated below.

Participants from public universities refereed to knowledge sharing through annual research weeks and research journals. Those from private institutions also discussed knowledge sharing through annual conferences.

"There were two elements which contributed to the sharing of knowledge at the university. The first one was the setting-up of the Research Journal in 1998, which has 
been available online since 2001 to facilitate dissemination of the research findings to a wide audience. The second one has been the setting-up of the research week, which is a major forum/ platform for sharing" (A2).

"We have an annual conference here and teaching and learning conference, where we share ideas with the public as well" (F).

Almost every academic institution involved in teaching and learning has regular departmental or curriculum meetings where, implicitly, some sort of knowledge sharing happens as was also reported by one participant.

"Within departments and subject groups, we have both formal and informal meetings, to talk not necessarily about new knowledge but about the knowledge we are sharing with students. So, we will have curriculum meetings and module meetings and if the module has lots of students than it is shared by a number of staff" $(F)$.

Private institutions that are affiliated with overseas universities have access to research repositories and other knowledge resource platforms through their parent institution, which promotes sharing and collaboration.

"We have got the formal research repository. Any time anyone publishes anything or writes anything they need to place it in the University research repository, which is open access. There is a big move in England to have all the research as open access and as freely as available, so we've done that" (F).

Participants from private sector HEI's mentioned regular informal knowledge sharing sessions organized within their institution, such as, learning hours and lunch-time seminars.

"We have a 'learning hour', which is all about sharing, the learning hour is only for academics, so once a week we meet and we share." (E)

"We have a sort of lunch time seminar... and open meetings and focused groups depending on needs. But we tend to have at least two or three all staff meetings a year for updates on how we are doing" (F).

Participants also linked their knowledge sharing practice with collective intelligence.

"We believe in collective intelligence, nobody knows everything we are aware about it, so somebody who doesn't share will not stay here long. The more you share the more you receive" (E). 


\subsubsection{Knowledge Transfer}

Participants from both from public and private HEIs, reported on their institution's involvement in knowledge transfer through different activities as summarized in Figure 3.

[Insert Figure 3 near here]

Knowledge transfer to industry through consultancies is restricted to a few public HEIs.

"We interact with industry, transferring knowledge to industry through consultancy to different stakeholders, government or industry" (A1).

In the remaining HEIs, knowledge transfer mainly occurs through their students joining the workforce, and organising bespoke courses and training programmes for public and private institutions.

"Firstly, our mission is to train students, through our trained graduates, which of course go into the workforce; we are transferring knowledge into the community" (A1).

"We are involved in producing tailor made training programmes for both the private and the public sector," (D).

One public university recently launched an innovative programme called 'community learning and engagement'. This programme tries to integrate community learning and social responsibility into undergraduate programmes to help in students' intellectual, personal, and professional development. Participants elaborated thus:

"The students have to be involved with society, so that they know exactly what the society needs and how they can help. It's like service to the society. This will build their values. When we collaborate with industry, and with NGOs we will learn more and we will know how to help" (B3).

Participants from one public university mentioned the establishment of a 'knowledge transfer office' as a new initiative, which might facilitate knowledge transfer.

"Knowledge transfer is very much an individual matter and we get called as consultants because people know what area we are in... Now the university has come up with this idea of a Knowledge Transfer Office; maybe that's going to help [in knowledge transfer]" (A3).

In the absence of a formal structure, one head a public university suggested that he took responsibility for knowledge transfer.

“As such we don't have an office of Knowledge Transfer/ Technology Transfer, but under my office, I tap the knowledge of the institution, as I know where it exists" (B1). 
Other mechanisms for knowledge transfer, such as, through research publications, participation in seminars/workshops/conferences and external committees and meetings, were reported by participants from both public and private HEIs.

"Transferring yes, we are doing a lot of research and publication in journals but we need another mechanism to transfer that knowledge in layman's language. More in a format of newsletter etc. so that the people know exactly what we are doing and not putting in scientific jargon etc. so that we are transferring the knowledge to the industry." (A1).

"We also participate in workshops, advisory committees and brainstorming sessions whenever we are invited, we go and participate and share our knowledge with them" (E).

\subsubsection{Summary}

Table 2 summarises the themes and sub themes of the KM processes used by HEIs. In addition, there is strong evidence that the three processes of knowledge creation, knowledge sharing and knowledge transfer are interrelated. This happens through a number of different processes. For example, knowledge created during teaching and learning activities by developing curriculum and course material during internal meetings, such as, departmental and curriculum meetings is transferred through trained students joining the workforce, organizing training programmes and CPDs and community engagement. In addition, knowledge created through research is shared among peers during seminars and conferences, which is ultimately transferred to outside partners through research publications in journals. Also, organizational knowledge created through developing academic policies, processes and procedures, manuals and handbooks, student charters, various reports and documents, notes of meetings during internal meetings, is transferred through annual reports and newsletters, which are sometimes posted on websites. Finally, it was evident that some activities, such as, consultancies and participation in seminars, workshops, conferences, internal and external committees and meetings, contribute to all the three knowledge management process: knowledge creation, knowledge sharing and knowledge transfer in HEIs of Mauritius.

\section{Discussion}

Firstly, the study found that most participants were familiar with the term, knowledge management, but that their institutions did not have a written KM strategy. This is consistent with previous work by Cranfield and Taylor (2008) and Trivella and Dimitrios (2015), however, lack of KM strategy does not prevent HEIs from k-creation, k-sharing and k-transfer, as these processes are closely linked to their missions (Rowley, 2000; Alexandropoulou et al., 2009; Ramachandran et al., 2009; Fullwood et al., 2013).

Secondly, the study confirmed that all institutions in the sample are involved in all three of knowledge creation and acquisition, knowledge sharing and knowledge transfer, and that participants were able to discuss the processes involved in knowledge creation and acquisition, sharing and transfer. 
Table 2: Summary of KM processes of HEIs in Mauritius

\begin{tabular}{|c|c|c|c|}
\hline Themes & Knowledge Creation & Knowledge Sharing & Knowledge Transfer \\
\hline \multirow[t]{7}{*}{$\begin{array}{l}\text { Sub- } \\
\text { themes }\end{array}$} & $\begin{array}{l}\text { Teaching and learning } \\
\text { activities }\end{array}$ & Internal meetings & Trained Students \\
\hline & Research & Research journal & Publications in Journals \\
\hline & $\begin{array}{l}\text { Organisational } \\
\text { documentation }\end{array}$ & Collaborative Platform & Website \\
\hline & Consultancies & & Consultancies \\
\hline & $\begin{array}{l}\text { Knowledge acquisition } \\
\text { from external sources }\end{array}$ & $\begin{array}{l}\text { Seminars and } \\
\text { Conferences }\end{array}$ & $\begin{array}{l}\text { Seminars and } \\
\text { Conferences }\end{array}$ \\
\hline & & & External meetings \\
\hline & & & Community Engagement \\
\hline
\end{tabular}

Even though previous studies on knowledge management in higher education agree that HEIs are knowledge creating institutions, they perceive only 'research', 'scientific discovery', 'scientific socialization' and 'acquisition of knowledge' from external sources as knowledge creation roles of HEIs (Serban and Luan, 2002; Alexandropoulou et al., 2009; Ramachandran et al., 2009; Sohail and Daud, 2009; Adhikari, 2010; Siadat et al., 2012). However, this study discovered additional facets of knowledge creation in HEIs. Knowledge creation in HEIs, as perceived by heads of institutions and senior academics in Mauritius, includes activities such as: teaching and learning (developing curriculum and course materials and preparing lectures); consultancies with public and private bodies; organisational documentation produced at the institutional level (academic policies, processes and procedures, manuals and handbooks, student charters, various reports and documents, and notes of meetings). Arguably, the reason for other studies not having identified these processes is that previous studies on KM in HEIs were either conceptual (Alexandropoulou et al., 2009; Adhikari, 2010) or quantitative surveys with academics (Ramachandran et al., 2009) and did not capture the views of senior management through an inductive approach. Another reason could be that the HEIs in Mauritius, both public and private, are mainly teaching institutions, with the exception of a few public institutions who are geared towards research and are aiming to become research-led institutions. This is supported by Ramachandran et al. (2009), who are also of the view that knowledge creation through research constitutes a core activity of academics in public institutions, while for private HEIs, the core business lies in teaching, with little emphasis given to research (Ramachandran et al., 2009). It is also interesting to note that Fullwood et al. (2013) relate engagement of academics in the UK in research, and teaching and learning activities to knowledge sharing as opposed to knowledge creation, as in this study. Furthermore, in another study by Ramachandran et al. (2009) in developing countries, the universities consider teaching and learning activities, white papers, policies, and reports as mechanisms to disseminate/transfer knowledge (Ramachandran et al., 2009) rather than as knowledge creation. 
Participants from both public and private institutions reported various knowledge sharing mechanisms, including: departmental and curriculum meetings, annual research seminars and conferences and publications in journals. These findings are broadly in consistent with past studies on KS in HEIs (Cheng et al., 2009; Fullwood et al., 2013). However, participants from two private HEIs also mentioned 'informal' knowledge sharing sessions in their institution, such as, learning hours and lunch-time seminars indicating presence of a 'private sector' culture and an environment to facilitate knowledge sharing (Arntzen et al., 2009; Tian et al., 2009; Fullwood et al., 2013; Howell and Annansingh, 2013).

Knowledge transfer with industry through consultancies is mainly restricted to a few public HEIs, as also reported in past studies in developing countries (Gera, 2012; Bano and Taylor, 2014). In the remaining HEIs it is limited to transfer associated with their students joining the workforce (Adhikari, 2010), and to organising bespoke courses and training programmes for public and private institutions (Bano and Taylor, 2014). This situation may result from a variety of factors including: the absence of a framework for developing these linkages; the small size of HEIs in Mauritius; the focus on teaching and learning; and, the lack of a strong research culture leading to a lack of knowledge transfer activities as reported in the past studies (Ramachandran et al., 2009, Gera, 2012; Bano and Taylor, 2014).

In addition, participants were found to be using 'knowledge sharing' and 'knowledge transfer' interchangeably, as also reported by Paulin and Suneson (2012). Furthermore, the study also provided evidence that some KM activities and processes contributed to more than one of knowledge creation, sharing and transfer. These findings are consistent with previous studies on KM practices and processes in HE (Tian et al., 2009; Gertner et al., 2011; Gera, 2012) and private firms (Andreeva and Kianto, 2011; Lee et al., 2013), which suggest that the KM processes are interrelated and, as such they all contribute to innovation in firms.

\section{Conclusions and recommendations}

This study contributes to research on knowledge management in higher education institutions (HEIs), by studying its processes through a case study based investigation in a country with a developing higher education sector, Mauritius.

Although participants could discuss $\mathrm{KM}$ processes, none of the participating institutions had a KM strategy. All institutions are involved in knowledge creation and acquisition, knowledge sharing, and knowledge transfer. In addition to research, knowledge was regarded as being created through teaching and learning activities, consultancies, organizational documentation and acquisition from external sources. Knowledge is shared among peers during departmental and curriculum meetings, through annual research seminars and during conferences and through publications in journals. Knowledge transfer with industry through consultancies is restricted mainly to a few public HEIs and in remaining HEIs it is limited to their students joining the workforce and to organising tailor-made courses and training programmes for public and private institutions. The study also provided evidence that KM activities and processes are closely interrelated and some processes contributed to more than one of knowledge creation, sharing and transfer. 
In summary, whilst HEIs are involved in knowledge management there was a lack of awareness of the importance of KM due to the absence of knowledge creation, sharing and transfer strategies. HEIs would benefit considerably from a more strategic approach to knowledge management and to be successful, universities should capitalise on the value of the knowledge created through sharing and transferring it to outside partners for its application and to benefit society.

It is therefore recommended that Mauritian HEIs must identify what knowledge management means for them and where knowledge resides within the institution to help them design a strategy that can facilitate the use of knowledge, which is created and/or acquired, shared and transferred for their competitive advantage. They need to develop knowledge management strategies and policies focusing on knowledge creation, sharing and transfer.

Further studies could usefully consider the perceptions of academics using a quantitative survey to capture views from a wider range of stakeholder groups (academics, higher education managers, students, and external partners). More generally, there is considerable scope for further research into knowledge management in the higher education sector in the region, as a basis for potential benchmarking between higher education institutions. Future studies could also investigate the use of information technologies that support knowledge creation (databases, research repositories), sharing (emails, intranets, IT-based collaborative platforms) and transfer (websites, internet, social media).

More widely, this study suggests that universities in developing countries understand the need for implicit or explicit knowledge management processes. Further research on knowledge management processes and policies in universities in both developed and developing countries can contribute to a more robust and insightful knowledge base in this area.

This study should enable policy makers in higher education, government and the private sector to facilitate adoption of more effective and efficient knowledge management practices. Such practices have the potential to lead to innovative outcomes, which, in turn, could enhance the competitive advantage of universities, and through increasing creation, sharing and transfer of knowledge from universities to private sector, benefit society.

Acknowledgements: The authors would like to acknowledge the support of the Mauritius Research Council.

\section{References}

Adhikari, D.R. (2010), "Knowledge management in academic institutions", International Journal of Educational Management, Vol. 22 No. 2, pp. 94-104.

Alexandropoulou, D. A., Angelis, V. A. and Mavri, M. (2009), "Knowledge management and higher education: present state and future trends", International Journal of Knowledge and Learning, Vol. 5 No.1, pp. 96-106. 
Andreeva, T. and Kianto, A. (2011), "Knowledge processes, knowledge-intensity and innovation: a moderated mediation analysis", Journal of Knowledge Management, Vol. 15 No. 6, pp. 1016-1034.

Arntzen, A.A.B., Worasinchai, L. and Ribière, V.M. (2009), "An insight into knowledge management practices at Bangkok University", Journal of Knowledge Management, Vol. 13 No. 2, pp. 127-144.

Bano, S. and Taylor, J. (2014), "Universities and the knowledge-based economy: perceptions from a developing country", Higher Education Research \& Development, Vol. 34 No. 2, pp. 242-255.

Cheng, M., Ho, J.S. and Lau, P.M. (2009), "Knowledge sharing in academic institutions : a study of Multimedia University Malaysia”, Electronic Journal of Knowledge Management, Vol. 7 No. 3, pp. 313-324.

Cranfield, D.J. and Taylor, J. (2008), "Knowledge management and higher education: a UK case study", Electronic Journal of Knowledge Management, Vol. 6 No. 2, pp. 85-100.

Dalkir, K. (2011), Knowledge Management in Theory and Practice, 2nd edition, Burlington: Elsevier Butterworth-Heinemann. Elsevier Inc.

Etzkowitz, H. and Leydesdorff, L. (2000), "The dynamics of innovation: from National Systems and "Mode 2" to a Triple Helix of university-industry-government relations", Research Policy, Vol. 29 No. 2, pp. 109-123.

Fullwood, R., Rowley, J. and Delbridge, R. (2013), "Knowledge sharing amongst academics in UK universities", Journal of Knowledge Management, Vol. 17 No. 1, pp. 123-136.

Gera, R. (2012), "Bridging the gap in knowledge transfer between academia and practitioners", International Journal of Educational Management, Vol. 26 No.3, pp. 252-273.

Gertner, D., Roberts, J. and Charles, D. (2011), "University-industry collaboration: A CoPs approach to KTPs", Journal of Knowledge Management, Vol. 15 No. 4, pp. 625-647.

Goh, S.K. and Sandhu, M.S. (2013), "Knowledge sharing among Malaysian academics: influence of affective commitment and trust", Electronic Journal of Knowledge Management, Vol. 11 No. 1, pp. 38-48.

Howell, K.E. and Annansingh, F. (2013), "Knowledge generation and sharing in UK universities: A tale of two cultures?", International Journal of Information Management, Vol. 33 No. 1, pp. 32-39.

Kinchin, I.M. and Streatfield, D. (2010), "Using Concept Mapping to Enhance the Research Interview", International Journal of Qualitative Methods, Vol. 9 No. 1, pp. 52-68.

Lee, V-H., Leong L-Y., Hew T-S and Ooi K-B. (2013), "Knowledge management: a key determinant in advancing technological innovation?", Journal of Knowledge Management, Vol. 17 No. 6, pp. 848-872.

Miles, M. and Huberman, A. (1994), Qualitative Data Analysis: An Expanded Sourcebook, Sage, Beverly Hills, CA

Nonaka, I. (1994), "Dynamic Theory Knowledge of Organizational Creation", Journal of Organization Science, Vol. 5 No. 1, pp. 14-37.

Paulin, D. and Suneson, K. (2012), "Knowledge Transfer, Knowledge Sharing and Knowledge Barriers - Three Blurry Terms in KM", The Electronic Journal of Knowledge Management, Vol. 10 No. 1, pp. 81-91.

Ramachandran, S.D., Chong, S.C. and Ismail, H. (2009), "The practice of knowledge management processes: a comparative study of public and private higher education institutions in Malaysia", Vine, Vol. 39 No.3, pp. 203-222. 
Rowley, J. (2000), "Is higher education ready for knowledge management?", International Journal of Educational Management, Vol. 14 No. 7, pp. 325-333.

Saunders, M., Lewis, P. and Thornhill, A. (2016), Research Methods for Business Students, $7^{\text {th }}$ ed., Pearson, England.

Schmitz, A., Teza, P., Dandolini, G. A. and De Souza, J. A. (2014), "Universities as Knowledge Intensive Business Services - A Systematic Literature Review and a Case Study of a Research Group", International Journal of Engineering and Innovative Technology, Vol. 3 No. 7, pp. 40-47.

Serban, A.M. and Luan, J. (2002), 'Overview of knowledge management', New Directions for Institutional Research, Vol. 2002 No. 113, pp. 5-16.

Siadat, S.A., Hoveida, R, Abbaszadeh, M. and Moghtadaie, L. (2012), "Knowledge creation in universities and some related factors", Journal of Management Development, Vol. 31 No. 8, pp. 845-872.

Sohail, M.S. and Daud, S. (2009), "Knowledge sharing in higher education institutions: Perspectives from Malaysia", Vine: The Journal of Information and Knowledge Management Systems, Vol. 39 No. 2, pp. 125-142.

Tian, J., Nakamori, Y. and Wierzbicki, A.P. (2009), "Knowledge management and knowledge creation in academia: a study based on surveys in a Japanese research university", Journal of Knowledge Management, Vol. 13 No. 2, pp. 76-92.

Trivella, L. and Dimitrios, N.K. (2015), "Knowledge Management Strategy within the Higher Education. The case of Greece", Procedia - Social and Behavioral Sciences, Vol. 175, pp. 488-495. 